Eylar, O. R. JUn. \& Schmid, E. L. (1959). J. gen. Microbiol. 20, 473-481

\title{
A Survey of Heterotrophic Micro-Organisms from Soil for Ability to Form Nitrite and Nitrate
}

\author{
By O. R. EYLAR, Jun. ANd E. L. SCHMIDT \\ Department of Bacteriology and Immunology, and Department of Soils, \\ University of Minnesota, Minneapolis, Minnesota, U.S.A.
}

SUMMARY: A total of 978 cultures of heterotrophic organisms were isolated from twelve actively nitrifying soils; each isolate was tested for ability to form nitrite or nitrate in glucose peptone broth. None of the isolates yielded substantial amounts of nitrite; concentrations found did not exceed $2 \mu \mathrm{g}$. nitrite- $\mathrm{N} / \mathrm{ml}$. Almost $7 \%$ of the isolates formed nitrite- $\mathrm{N}$ in excess of $0.2 \mu \mathrm{g} . / \mathrm{ml}$., while slightly over $2 \%$ yielded more than $0.5 \mu \mathrm{g} . / \mathrm{ml}$. Fungus isolates were the most numerous and most active nitrite producers; fifteen of the fungi formed nitrate in addition to nitrite. Concentrations of 5-45 $\mu \mathrm{g}$. nitrate- $\mathrm{N} / \mathrm{ml}$. were recorded for the active fungi. Further isolations of fungi from ten soils of diverse properties resulted in 353 cultures but only three of these formed nitrate. One of these cultures yielded $90 \mu \mathrm{g}$. nitrate- $\mathrm{N} / \mathrm{ml}$. after 14 days growth in the test medium.

Most of the fungi which produced nitrate (16 of the 18 active cultures) were identified as Aspergillus flavus. A Penicillium sp., and a Cephalosporium sp. also formed low concentrations of nitrate. Each isolate of $A$. flavus obtained from soil proved capable of nitrate formation. Strains of $A$. flavus were encountered which did not yield nitrate, but these had been obtained from culture collections, and had been carried on artificial media for many years. Some stock cultures of $A$. flavus, several cultures of $\boldsymbol{A}$. flavus and one of $\boldsymbol{A}$. glaucus, freshly isolated from wheat seed, also were active nitrate producers. Ammonium sulphate and urea media supported growth of soil fungus isolates but not nitrate formation. Other organic nitrogen substrates in order of increasing effectiveness in nitrate production were: yeast extract, peptone, Protone and casein.

The possibility that autotrophic bacteria of the family Nitrobacteraceae are not the sole agents of nitrification has been considered many times. Reviews of the early literature by Barritt (1933), Stephenson (1939) and Waksman (1946) mention scattered claims for the isolation of heterotrophic microorganisms capable of effecting nitrification reactions. Stephenson (1939) expressed what appears to be an accepted interpretation of these papers: 'Numerous instances reported in the literature of nitrification occurring in organisms growing heterotrophically have been examined, and serious objections to the technique have been made in every case.' Renewed interest in nitrification by heterotrophic micro-organisms is justified by a number of reports. Study of the transformations of pyruvic acid oxime in soil led Quastel \& Scholefield (1949) to conclude that heterotrophic forms, rather than autotrophic nitrifying bacteria, oxidized the oxime to nitrite. Several bacteria, identified as belonging to two species of Achromobacter and one species of Corynebacterium, were reported later to be responsible for this transformation (Quastel, Scholefield \& Stevenson, 1950, 1952). Jensen (1951) isolated three more groups of heterotrophic micro-organisms which formed nitrite from the 
oxime of pyruvic acid: 24 strains of Nocardia corallina, 1 strain of Agrobacterium sp., 3 strains of Alcaligenes sp. were listed. One $N$. corallina culture produced $40 \mu \mathrm{g}$. nitrite- $\mathrm{N} / \mathrm{ml}$. in 8 days with pyruvic oxime as the only nitrogen source, and $70 \mu \mathrm{g}$. nitrite- $\mathrm{N} / \mathrm{ml}$. in oxime + peptone medium.

A new species of actinomycete, Streptomyces nitrificans, was described for its ability to oxidize ethylurethane to nitrite (Schatz, Isenberg, Angrist \& Schatz, 1954; Isenberg et al. 1954). The quantity of nitrite formed was extremely small; cultures grown for 68 days on $0 \cdot 2 \%(\mathrm{w} / \mathrm{v})$ ethylurethane produced only about $0.07 \mu \mathrm{g}$. nitrite-N/ml. Fisher, Fisher \& Appleman (1956) isolated sixteen Gram-negative to Gram-variable rod-shaped soil bacteria which formed nitrite in soil extract + ammonia media. Nitrite-N was limited to a maximum of about $10 \mu \mathrm{g} . / \mathrm{ml}$. in 3 weeks, and the origin of the nitrite was in doubt. Several methane oxidizing bacteria were shown by Hutton \& ZoBell (1953) to oxidize ammonium chloride to nitrite in a defined medium. While it is not possible to calculate with certainty from their data, it appears that about $20 \mu \mathrm{g}$. nitrite- $\mathrm{N} / \mathrm{ml}$. were produced during 19 days of incubation.

While a number of rather different groups of micro-organisms isolated from soil have been shown to form nitrite in pure culture, only one heterotroph has been implicated in the formation of nitrate. Schmidt (1954) reported the isolation of a soil fungus, Aspergillus flavus, which formed substantial concentrations of nitrate when grown in a yeast-extract + peptone + glucose broth. The nitrate-N concentration realized in some cases exceeded $35 \mu \mathrm{g} . / \mathrm{ml}$. in 2-3 weeks. Nitrite was also formed, but in negligible amounts.

The results of the pure culture studies cited may not be extrapolated directly to assess the contribution of heterotrophic micro-organisms to nitrification reactions in the soil. Before a realistic appraisal of their importance can be made, much more work is needed to observe the occurrence of 'heterotrophic nitrifiers' in soils, to characterize the physiological features of the organisms, to define the cultural conditions which lead to nitrite and nitrate formation, and to demonstrate the existence in soil of adequate specific substrates. The present report summarizes data obtained in a survey of the heterotrophic populations of numerous soils for the occurrence of microorganisms which might participate in the formation of nitrite and nitrate, and something of the nature and properties of such organisms.

\section{METHODS}

Twenty-two soil samples were used in the study. The first twelve samples were field and barn-yard soils collected from sites in Minnesota shown to have high to very high nitrifying capacities (Schmidt, 1956); the remaining ten samples were selected to represent soils of widely different physical and chemical properties, and have been characterized elsewhere (Schmidt \& Ruschmeyer, 1958).

Media used in the isolation and testing of soil organisms were chosen after preliminary experiments which indicated that the addition of ammonia to 
organic nitrogen sources did not increase the frequency with which heterotrophic nitrifying forms were obtained. Further trials suggested that direct isolation of micro-organisms from soil was as effective as isolation from enrichment cultures which had been inoculated with soil and then allowed to develop a strong nitrite test.

The procedure adopted for routine isolation of bacteria and actinomycetes involved plating of dilutions prepared from fresh soil in a medium of the following composition $(\%, w / v)$ : glucose, $0 \cdot 2$; peptone, $0 \cdot 4$; yeast extract, $0 \cdot 1$; dibasic potassium phosphate, $0 \cdot 1$; magnesium sulphate, 0.05 ; ferrous sulphate, 0.001; manganese sulphate, 0.001 ; agar, 1.5. Rose bengal and streptomycin were added to this medium for plating the fungi (Martin, 1950). Every colony which appeared to be distinctive on macroscopic and microscopic examination was transferred to a slope of the isolation medium and maintained in culture until tested. Only fungi were isolated from the last ten soil samples.

Isolates were tested for ability to form nitrite and/or nitrate after growth for 14 days under static or shaken conditions in a liquid glucose peptone medium of the composition as given above, but with the yeast extract omitted. Glucose and peptone solutions were sterilized separately from the salts solution and added aseptically. Each culture was tested qualitatively for nitrite and nitrate; when either was positive, nitrite was determined quantitatively by the Griess-Ilosvay reagents and nitrate by the phenoldisulphonic method (both as outlined by Snell \& Snell, 1949). Uninoculated medium was analysed in each experiment and maximum values did not exceed $0 \cdot 02 \mu$ g. nitrite- $\mathrm{N} / \mathrm{ml}$. or $2 \cdot 0 \mu \mathrm{g}$. nitrate- $\mathrm{N} / \mathrm{ml}$.

\section{RESULTS}

Studies of twelve soils known to have high nitrifying capacity resulted in the isolation and testing of $\mathbf{9 7 8}$ cultures of heterotrophic organisms. The occurrence among these isolates of forms which produced measurable amounts of nitrite or nitrate is summarized in Table 1 . With $0 \cdot 2 \mu \mathrm{g}$. nitrite- $\mathrm{N} / \mathrm{ml}$. accepted as a

Table 1. Micro-organisms isolated from twelve soils of high nitrifying capacity and the incidence forms capable of producing nitrite and nitrate when grown on glucose peptone medium

\begin{tabular}{|c|c|c|c|c|}
\hline \multirow[b]{2}{*}{ Isolates } & \multirow{2}{*}{$\begin{array}{c}\text { Total } \\
\text { number }\end{array}$} & \multicolumn{2}{|c|}{$\begin{array}{l}\text { No. which formed } \\
\mathrm{NO}_{2}-\mathrm{N} \text { in excess of }\end{array}$} & \multirow{2}{*}{$\begin{array}{l}\text { No. which } \\
\text { formed } \mathrm{NO}_{3}-\mathrm{N} \\
\text { in excess of } \\
5.0 \mu \mathrm{g} . / \mathrm{ml} \text {. }\end{array}$} \\
\hline & & $0.2 \mu \mathrm{g} . / \mathrm{ml}$ & $0.5 \mu \mathrm{g} . / \mathrm{ml}$. & \\
\hline Actinomycetes & 222 & 16 & $\mathbf{1}$ & $\mathbf{0}$ \\
\hline Bacteria & 341 & 24 & 8 & 1 \\
\hline Fungi & 415 & 26 & 14 & 15 \\
\hline Total & 978 & 66 & 23 & 16 \\
\hline
\end{tabular}

threshold value (10 times the maximum encountered in control media) 66 of the 978 cultures proved capable of forming nitrite. It is clear that this number of 'nitrite producers' (c. $7 \%$ of the isolates) would be substantially smaller if a higher concentration of nitrite were considered; few of the cultures produced 
nitrite- $\mathrm{N}$ in excess of $0.5 \mu \mathrm{g} . / \mathrm{ml}$. and most of those were fungi. The fungus isolates were of further interest for, as noted in Table 1, they were almost exclusively responsible for any nitrate observed.

The production of nitrite and nitrate by the most active isolates is show $n$ in Table 2 which gives the concentrations (as nitrogen equivalents) attained. In no instance was there substantial accumulation of nitrite; the maximum concentration realized was equivalent to $1 \cdot 80 \mu \mathrm{g}$. nitrate- $\mathrm{N} / \mathrm{ml}$.; and this must be considered very low in comparison with nitrite formation by classical autotrophic nitrifying bacteria. Among the fungus isolates which yielded the most nitrite it is clear, from Table 2 , that all save one produced nitrate in addition to nitrite. Moreover, with the exception of a single bacterial culture, the only forms which did produce nitrate were fungi.

Table 2. Production of $\mathrm{NO}_{2}-\mathrm{N}$ and/or $\mathrm{NO}_{3}-\mathrm{N}$ by soil isolates grown in glucose + peptone medium, and incubated for 14 days in static or shaken culture

\begin{tabular}{|c|c|c|c|c|}
\hline \multirow[b]{2}{*}{ Organism* } & \multicolumn{2}{|c|}{$\mathrm{NO}_{2}-\mathrm{N}(\mu \mathrm{g} . / \mathrm{ml})}$. & \multicolumn{2}{|c|}{$\mathrm{NO}_{3}-\mathrm{N}(\mu \mathrm{g} \cdot / \mathrm{ml})}$. \\
\hline & Static & Shaken & Static & Shaken \\
\hline F-1-0 & $1 \cdot 80$ & 0.80 & $26 \cdot 1$ & $26 \cdot 5$ \\
\hline B-2-14 & $0 \cdot 15$ & $1 \cdot 66$ & 0.0 & 0.0 \\
\hline F-2-3 & 0.54 & 0.53 & $\mathbf{3 \cdot 2}$ & $0 \cdot 0$ \\
\hline F-2-5 & 0.60 & 0.45 & $15 \cdot 4$ & $0 \cdot 0$ \\
\hline B-3-3 & 0.00 & 0.91 & 0.0 & 0.0 \\
\hline B-3-4 & 0.06 & 0.66 & $0 \cdot 0$ & $0 \cdot 0$ \\
\hline B-4-2 & 0.05 & 0.50 & 0.0 & $0 \cdot 0$ \\
\hline B-4-6 & 0.03 & $0 \cdot 60$ & 0.0 & $0 \cdot 0$ \\
\hline F-4-6 & 0.02 & $0 \cdot 70$ & 0.0 & 0.0 \\
\hline F-5-4 & $0 \cdot 38$ & $1 \cdot 60$ & $10 \cdot 0$ & $19 \cdot 4$ \\
\hline F-6-32 & 1.49 & $0 \cdot 27$ & 30.8 & $15 \cdot 5$ \\
\hline B-7-18 & 0.03 & 0.61 & $0 \cdot 0$ & $0 \cdot 0$ \\
\hline A-8-2 & 0.98 & $1 \cdot 46$ & 0.0 & $0 \cdot 0$ \\
\hline B-8-12 & 0.03 & 0.56 & 0.0 & $0 \cdot 0$ \\
\hline F-9-2 & 0.84 & $1 \cdot 03$ & $10 \cdot 8$ & $5 \cdot 5$ \\
\hline F-9-8 & $0 \cdot 70$ & 1.08 & $32 \cdot 8$ & $8 \cdot 9$ \\
\hline F-9-10 & 0.88 & $0 \cdot 86$ & $45 \cdot 0$ & $11 \cdot 1$ \\
\hline F-9-11 & 0.54 & $1 \cdot 12$ & $24 \cdot 5$ & $2 \cdot 9$ \\
\hline F-9-20 & 0.41 & 0.41 & 21.5 & $12 \cdot 2$ \\
\hline F-9-21 & 0.42 & 0.42 & $10 \cdot 4$ & $9 \cdot 8$ \\
\hline F-9-22 & 0.52 & 0.57 & $19 \cdot 3$ & $15 \cdot 0$ \\
\hline F-9-23 & 0.81 & 0.48 & $9 \cdot 3$ & $9 \cdot 7$ \\
\hline F-9-25 & $1 \cdot 28$ & $0 \cdot 38$ & 20.5 & $\mathbf{9} \cdot \mathbf{3}$ \\
\hline F-11-25 & $0 \cdot 46$ & $0 \cdot 46$ & $27 \cdot 5$ & $11 \cdot 0$ \\
\hline F-11-26 & 0.39 & 0.39 & $12 \cdot 3$ & $8 \cdot 6$ \\
\hline B-12-21 & 0.02 & $0 \cdot 29$ & $11 \cdot 0$ & 0.8 \\
\hline
\end{tabular}

* $\mathbf{A}=$ actinomycete $; \mathbf{B}=$ bacteria $; \mathbf{F}=$ fungus. Further designations refer to soil and isolate numbers.

Nitrate production by the fungi was much more variable than nitrite production, but concentrations as high as $45 \mu \mathrm{g}$. nitrate- $\mathrm{N} / \mathrm{ml}$. were attained by certain of the isolates. Static culture gave nitrate concentrations usually as high and generally much higher than those obtained under shaken conditions. The one bacterium which evinced ability to produce nitrate (isolate B-12-21) was of much interest as we are not aware of any report in the literature that has 
associated a heterotrophic bacterium with nitrate formation. As further trials with this culture gave very erratic results, an evaluation of the isolate has been left for further experiment.

The substantial concentrations of nitrate produced by some isolates and the obvious importance of fungi in the transformation suggested that a variety of soils should be studied, with emphasis on the occurrence of fungi capable of nitrate formation. In Table 3 are presented the results of testing fungal isolates from ten soils of widely different physical and chemical features. Only three active cultures were found among the 353 isolates tested, but one of these (isolate $\mathrm{F}-16-1$ ) yielded $90 \mu \mathrm{g}$. nitrate- $\mathrm{N} / \mathrm{ml}$. in static culture.

\section{Table 3. Active fungal isolates}

The three active fungal isolates obtained from ten soils of diverse properties, and $\mathrm{NO}_{2}-\mathrm{N}$ and/or $\mathrm{NO}_{3}-\mathrm{N}$ produced by each in glucose + peptone medium during 14 days incubation at $28^{\circ}$, in static or shaken culture. Only isolates which formed $\mathrm{NO}_{2}-\mathrm{N}$ in excess of $0.5 \mu \mathrm{g} . / \mathrm{ml}$. or $\mathrm{NO}_{3}-\mathrm{N}$ in excess of $5 \mu \mathrm{g} . / \mathrm{ml}$. are reported; 353 fungal isolates were studied.

$\begin{array}{lccccc} & \mathrm{NO}_{2}-\mathrm{N}(\mu \mathrm{g} . / \mathrm{ml} .) & & \mathrm{NO}_{3}-\mathrm{N}(\mu \mathrm{g} . / \mathrm{ml} .) \\ \text { Isolate } & \text { Static } & \text { Shaken } & \text { Static } & \text { Shaken } \\ \text { F-13-34 } & 0.00 & 0 \cdot 00 & 14 \cdot 0 & 0 \cdot 0 \\ \text { F-16-1 } & 0.89 & 1 \cdot 05 & 90 \cdot 0 & 45 \cdot 0 \\ \text { F-19-23 } & 0.15 & 0 \cdot 00 & 11 \cdot 8 & 0.0\end{array}$

In all, twenty fungal isolates were found to produce nitrite and/or nitrate. A classification of these isolates is given in Table 4. Seventeen of the twenty cultures proved to be Aspergillus flavus. Throughout the present work it was observed that every isolate of $A$. flavus recovered from soil was capable of forming nitrate. Moreover, these data show that the very unusual property of nitrate formation was limited almost exclusively to $A$. flavus, for only two among the 751 isolates of other fungal species formed even a trace of nitrate. One isolate (F-13-34) yielded 14.0 $\mu \mathrm{g}$. nitrate- $\mathrm{N} / \mathrm{ml}$, and isolate $\mathrm{F}-19-23$ a Penicillium) produced $11.8 \mu \mathrm{g}$. nitrate- $\mathrm{N} / \mathrm{ml}$. Another Penicillium isolate (F-4-6) formed nitrite but not nitrate.

Included also in Table 4 are the results of experiments in which the fungal isolates were grown in media containing nitrogen sources other than peptone. The isolates grew well in all media, but neither ammonia nor urea as nitrogen sources resulted in the accumulation of nitrite or nitrate. Yeast-extract nitrogen was not as good as peptone, while results with the Protone nitrogen (predominantly proteoses) approximated those obtained in peptone media. Casein was clearly the most suitable nitrogen source for the production of nitrite and nitrate by most of the fungal isolates.

The consistent ability of soil isolates of Aspergillus flavus to produce nitrate, and the failure to find soil fungi other than $A$. flavus with this capacity, prompted an examination of aspergilli obtained from sources other than soil. Twenty isolates of the $A$. flavus group and a few representatives of other groups of aspergilli were gathered from a number of culture collections. Growth in static culture for 14 days in the glucose peptone medium gave the results 


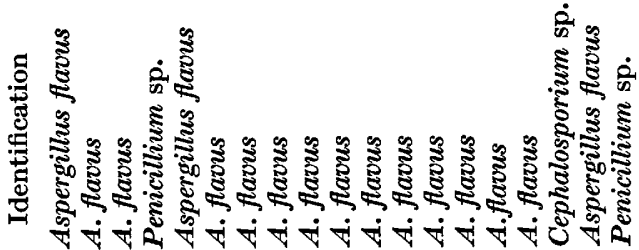


listed in Table 5. Only six of the thirteen isolates of A. flavus which were taken from stock culture collections formed significant amounts of nitrate. It is possible that continued subcultivation on ordinary laboratory media may modify the ability of an $A$. flavus strain to form nitrate or nitrite. Culture isolates CMC 1-7 had only recently been isolated from wheat seeds and all but one of these isolates gave very high yields of nitrate-N. The results of testing a few cultures of Aspergillus other than A. flavus showed that nitrate production was not restricted to the flavus-oryzae group. The fresh isolate of $\boldsymbol{A}$. glaucus formed nitrate in quantity comparable to that produced by the fresh isolates of $\boldsymbol{A}$. flavus. It does not seem likely, however, that nitrate production is a common feature of aspergilli outside of the flavus-oryzae group, for it was observed that the 751 fungi isolated from soil in this study included a number of Aspergillus species and only the A. flavus isolates proved to be active.

Table 5. Formation of nitrite and nitrate by Aspergillus cultures not obtained directly from soil

Cultures incubated statically in glucose + peptone medium for 14 days.

Yield as $\mu \mathrm{g} . \mathrm{N} / \mathrm{ml}$.

\begin{tabular}{|c|c|c|c|}
\hline Isolate & Source & $\mathrm{NO}_{2}--\mathrm{N}$ & $\mathrm{NO}_{3}-\mathbf{- N}$ \\
\hline A. flavus 9807 & & $\mathbf{0 . 3 0}$ & $4 \cdot 9$ \\
\hline A. flavus 10124 & Upjohn Co. laboratories & $0 \cdot 15$ & $4 \cdot 6$ \\
\hline A. flavus 9296 & & 0.05 & $\mathbf{3 \cdot 1}$ \\
\hline A. flavus 9170 & & $0 \cdot 09$ & $\mathbf{3} \cdot \mathbf{5}$ \\
\hline A. flavus 871 & & $0 \cdot 68$ & $37 \cdot 1$ \\
\hline A. flavus $4 \mathrm{~m}$ & Quartermaster collection & $0 \cdot 33$ & $14 \cdot 0$ \\
\hline A. flavus $63 \mathrm{c}$ & & $0 \cdot 31$ & $27 \cdot 0$ \\
\hline A. flavus $\mathbf{3 8 0}$ & & $0 \cdot 65$ & $18 \cdot 4$ \\
\hline A. flavus 301 & University of Minnesota & $0 \cdot 28$ & $16 \cdot 7$ \\
\hline A. flavus 453 & & $0 \cdot 29$ & $14 \cdot 6$ \\
\hline A. flavus 489 & U.S.D.A. Peoria, Ill. & 0.09 & $1 \cdot 0$ \\
\hline A. flavus 625 & & 0.04 & $1 \cdot 0$ \\
\hline A. flavus 2222 & & $0 \cdot 35$ & $11 \cdot 7$ \\
\hline A. flavus CMC 1 & & $0 \cdot 60$ & $13 \cdot 0$ \\
\hline A. flavus 2 & & 0.53 & $81 \cdot 0$ \\
\hline A. flavus 3 & & 0.58 & $93 \cdot 0$ \\
\hline A. flavus 4 & Wheat seed, University of Minnesota & $0 \cdot 41$ & $41 \cdot 4$ \\
\hline A. flavus 5 & & $0 \cdot 4,1$ & $80 \cdot 0$ \\
\hline A. flavus 6 & & $0 \cdot 46$ & $81 \cdot 0$ \\
\hline A. flavus 7 & & 0.51 & $78 \cdot 7$ \\
\hline A. glaucus CMC8 & & $0 \cdot 31$ & $52 \cdot 0$ \\
\hline A. oryzae 692 & & $0 \cdot 05$ & 1.5 \\
\hline A. terreus 1960 & U.S.D.A. Peoria, Ill. & 0.04 & 1.5 \\
\hline A. fumigatus 1986 & & $0 \cdot 04$ & $1 \cdot 5$ \\
\hline A. niger 328 & & 0.40 & $\mathbf{1 \cdot 5}$ \\
\hline Control medium & & 0.04 & $\mathbf{1 \cdot 5}$ \\
\hline
\end{tabular}

\section{DISCUSSION}

None of the 1331 soil isolates examined in this survey formed nitrite in significant concentrations; certainly none approached the standards cited for Nitrosomonas (Meiklejohn, 1953) or the concentrations achieved by the more active Nocardia of Jensen (1951). Less than $2 \%$ of all isolates formed nitrite-N 
in excess of $0.5 \mu \mathrm{g} . / \mathrm{ml}$, , while approximately $5 \%$ formed nitrite- $\mathrm{N}$ in excess of $\mathbf{0 . 2} \mu \mathrm{g} . / \mathrm{ml}$. In the first twelve soils examined, where all groups were studied, $27 \%$ of the actinomycetes, $26 \%$ of the bacteria, and $17 \%$ of the fungi formed at least a measurable amount of nitrite. The results of these experiments suggest that very limited nitrite formation may be a potentiality of a sizeable and diverse segment of the soil microflora, but that heterotrophic forms capable of substantial degrees of nitrite production either occur rarely in soil or were not disclosed by the procedures used.

Nitrate formation by heterotrophic organisms, in contrast to nitrite formation, was observed at substantial concentrations and was limited to a specific segment of the soil microflora. Aspergillus flavus merits special attention in any consideration of nitrate production. This fungal species is widely distributed in soils (Thom \& Raper, 1945), was the first heterotrophic organism reported to produce nitrate (Schmidt, 1954), and accounted for nearly all instances of nitrate formation observed in this survey. One or more isolates of $A$. flavus were obtained from eight of the twenty-two sites studied, and isolation was made more commonly from the twelve soils of high nitrifying capacity than from ten other sites selected for other properties. Each $A$. flavus isolate obtained from soil proved capable of some nitrate formation in the test medium. Cultures of $A$. flavus demonstrated considerable variability in nitrate production whether obtained from soil (Table 4) or from other sources (Table 5). The nature of the nitrogen source, the aeration of the medium, and the history of subculture, all apparently affected the amount of nitrate produced.

The simple forms of nitrogen such as ammonia and urea allowed for good growth but no nitrate formation, while more complex nitrogenous materials were clearly superior as substrates for nitrate production (Table 4). It is possible that nitrate formed by $A$. flavus actually is derived from ammonia as in autotrophic nitrification, but that synthesis of the appropriate enzymes requires a complex medium; Schmidt (1954) showed that ammonia is formed along with nitrate in peptone media. Information as to the nature of specific components of the complex nitrogen sources that are a prerequisite to nitrate formation will help assess the importance of $A$. flavus as a nitrate producer in mixed culture in soil. Attempts to identify such active components are in progress.

This investigation was supported by research grants E-248 and E-1709 from the National Institutes of Health, U.S. Public Health Service. The authors are indebted to Dr C. M. Christensen, Department of Plant Pathology; The Upjohn Company, Kalamazoo, Michigan; U.S. Department of Agriculture Regional Laboratories, Peoria, Illinois; and U.S. Army Quartermaster, Natick, Massachusetts, for some of the cultures used in this study. Paper number 3985 of the Scientific Journal Series, University of Minnesota Agricultural Experiment Station.

\section{REFERENCES}

BarRitT, N. W. (1933). The nitrification process in soils and biological filters. Ann. appl. Biol. 20, 165.

Fisher, T., Fisher, E. \& Appleman, M. D. (1956). Nitrite production by heterotrophic bacteria. J. gen. Microbiol. 14, 238. 
Hutron, W. E. \& ZoBell, C. E. (1953). Production of nitrite from ammonia by methane oxidizing bacteria. J. Bact. 65, 216.

Isenberg, H. D., Schatz, A., Angrist, A. A., Schatz, V. \& Trelawny, G. S. (1954). Microbial metabolism of carbamates. II. Nitrification of urethan by Streptomyces nitrificans. J. Bact. 68, 5 .

JENSEN, H. L. (1951). Nitrification of oxime compounds by heterotrophic bacteria. J. gen. Microbiol. 5, 360.

Martin, J. P. (1950). Use of acid, rose bengal and streptomycin in the plate method for estimating soil fungi. Soil Sci. 69, 215.

Meiklejohn, J. (1953). The nitrifying bacteria: A review. J. Soil Sci. 4, 59.

Quastel, J. H. \& Scholefield, P. G. (1949). Influence of organic nitrogen compounds on nitrification in soil. Nature, Lond. 164, 1068.

Quastel, J. H., Scholefield, P. G. \& Stevenson, J. W. (1950). Oxidation of pyruvic oxime by soil organisms. Nature, Lond. 166, 940.

Quastex, J. H., Scholefield, P. G. \& Stevenson, J. W. (1952). Oxidation of pyruvic oxime by soil organisms. Biochem. J. 51, 278.

Schatz, A., Isenberg, H. D., Angrist, A. A. \& Schatz, V. (1954). Microbial metabolism of carbamates. I. Isolation of Streptomyces nitrificans, n.sp., and other organisms which grow on urethan. J. Bact. 68, 1.

Schmidt, E. L. (1954). Nitrate formation by a soil fungus. Science, 119, 187.

Scнмidт, E. L. (1956). Soil nitrification and nitrates in waters. Publ. Hlth Rep. 71, 497.

Schmidt, E. L. \& Ruschmeyer, O. R. (1958). Cellulose decomposition in soil burial beds. I. Soil properties in relation to cellulose degradation. Appl. Microbiol. 6, 108.

SNell, F. D. \& SNell, C. T. (1949). Colorimetric Methods of Analysis, vol. II, third edition. New York: D. van Nostrand.

Stephenson, M. (1939). Bacterial Metabolism, second edition. London: Longmans, Green and Co.

Thом, C. \& RAPEr, K. B. (1945). A Manual of the Aspergilli. Baltimore, Md., U.S.A.: Williams and Wilkins.

Waksman, S. A. (1946). Sergi Nikolaevitch Winogradsky. Soil Sci. 62, 197. 